\title{
The Contribution of Symmetrical in Different Analysis Methods for Plane Frame: A Critical Review
}

\author{
Sedeeq, A. A ${ }^{1}$, Karim, F. $\mathrm{R}^{2^{*}}$ \\ ${ }^{1}$ College of Engineering, Department of Civil Engineering, University of Sulaimani, Iraq \\ ${ }^{2}$ Lecturer, College of Engineering, Civil Eng. Department, University of Sulaimani, Iraq
}

DOI: $10.36348 /$ sjce.2020.v04i01.001

| Received: 14.01.2020 | Accepted: 21.01.2020 | Published: 24.01.2020

*Corresponding author: Dr. Ferhad Rahim Karim

\section{Abstract}

This paper highlight, the techniques used to analyses symmetric structures subject to general loading. After an extensive review of previous work in this field, the paper introduces the most public way of structure analysis, based on conventional three methods which is force, matrix stiffness and column analogy techniques. It shows how this approach can systematically simplify a structural analysis and clarify a technique which is best known to structural engineers. For each method, a portal symmetry plane frame considered for analyzing with an explanation of the analysis calculation procedure, and it also shows that the influences of symmetry can observe and utilization in different methods to simplify the analysis procedure.

Keywords: Force, Column analogy, Stiffness, Structural analysis methods, Symmetry.

Copyright @ 2020: This is an open-access article distributed under the terms of the Creative Commons Attribution license which permits unrestricted use, distribution, and reproduction in any medium for non-commercial use (NonCommercial, or CC-BY-NC) provided the original author and source are credited.

Table-1: Symbols and Abbreviation

\begin{tabular}{|c|c|}
\hline Symbol & Description \\
\hline B.M.D & Bending Moment diagram \\
\hline $\mathrm{D}$ & Joint Displacement \\
\hline C.G & Center of gravity \\
\hline D.S.I & Degree of statically indeterminacy \\
\hline D.K.I & Degree of kinematic indeterminacy \\
\hline EI & Flexural Rigidity \\
\hline e & Eccentricity \\
\hline $\mathrm{F}$ & Flexibility \\
\hline $\mathrm{F}^{-1}$ & Flexibility inverse \\
\hline $\mathrm{H}$ & Horizontal Reaction \\
\hline $\mathrm{I}$ & Moment of inertia \\
\hline $\mathrm{L}$ & Length of Element \\
\hline $\mathrm{j}$ & Joint \\
\hline $\mathrm{P}$ & Point Load \\
\hline $\mathrm{Q}$ & Redundant action \\
\hline $\mathrm{r}$ & Restrain \\
\hline S.F.D & Shear Force Diagram \\
\hline $\mathrm{V}$ & Vertical Reaction \\
\hline$\Delta$ & Displacement \\
\hline
\end{tabular}

\section{INTRODUCTION}

Comprehending the relationships between the structural arrangement of nature and physical properties is one of the significant challenges in functional materials, exclusively given engineering new compounds because symmetry is a natural form that widely studied in different study fields.

The concept of symmetry has an ancient origin in considerations of visual appearance, from Greek writing

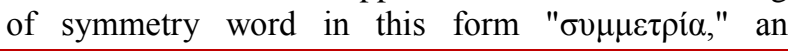


agreement in dimensions, a due proportion detects, arrangement in daily language refers to a sense of harmonious and balanced a proportion of symmetry. The technique of symmetry analysis originated in the 1870 s and developed by Sophus Lie and is therefore named Lie group analysis method. The method can find the symmetries of almost any system of differential equations, and the knowledge of these symmetries can simplify the analysis of physical and structural analysis problems governed by the equations.

From early time symmetry form finds approach into architecture at every scale, from the external visions of buildings such as Gothic cathedrals and the White House, through the layout of individual floor plans, and down to the design of individual building elements such as mosaic tiles in Islamic buildings like Taj Mahal and Lotfollah mosque by using of symmetry in their structure and decoration, Moorish buildings like the Alhambra ornamented with intricate patterns made using translational and reflection symmetries as well as rotations.

Symmetry in a structural system can effectively exploit to analyze structural systems. Symmetry can found in many real-life structural systems or (in the idealized model of a real-life skeletal system). It is essential to remember that when we say symmetry in a structural system, it implies the existence of equality both in the structure itself, excluding the support settings and additionally in the loading on that structure. Asymmetric structure can be recognized by examination simply compare the geometry, supports, and material properties of the two halves of the structure on each side of the axis of symmetry. In common with other parts of structural analysis, there has been an increase in the effort done in this zone since the advent of the electronic computer and especially since the development of finite element structural analysis packages.

Several structures, because of artistic and purposeful considerations, are arranged in symmetric designs. Recognition of such symmetry will identify, and the use of this symmetry reduces the computational effort in analyzing such a structure. When a symmetric structure subjected to a loading concerning the structure's axis of symmetry, the response of the structure is also symmetric.

In civil engineering construction projects, most structures loads, and the strength of objects depend on the symmetry. In these cases, it's possible to take advantage of symmetry to simplify the calculation procedures of structural analysis of elements. During recent decades, various simplification approaches for reducing the process and computation time have developed.

\section{LITERATURE REVIEW}

The progress of using the benefit of the symmetry properties in a structural analysis method does not have defended origin nor a continuous historical pathway. In common with other zones of structural analysis, there has been an increase in the effort done in this zone since the beginning of the computer application and especially since the growth of finite element structural analysis packages. However, the fundamental ideas are not generally known in the structural engineering community; the benefit of symmetry properties has not been exploited and developed Kangway 1999.

In 1864, James Clerk Maxwell published the first consistent force method for analyzing statically indeterminate structures. His approach based on a consideration of deflections, but the presentation (which included the reciprocal deflection theorem) was rather brief and attracted little attention. Ten years later, Otto Mohr independently extended the theory to almost its present stage of development. Analysis of redundant structures with the use of deflection computations often referred to as the Maxwell- Mohr method or the method of consistent distortions. The force methods of structural analysis are somewhat useful for analyzing beams, frames, and trusses that are statically indeterminate to the first or second degree; it also is convenient for some single-story frames with unusual dimensions.

For structures that are highly statically indeterminate, such as multi-story buildings and large, intricate trusses, other methods are more appropriate and useful. These methods, which include moment distribution and the matrix methods, are more satisfactory; as such, the force methods almost completely superseded. It will provide an understanding of the behavior of statically indeterminate structures that might not otherwise obtained.

In the displacement methods of analysis, the displacement of the joints (rotations and translations) necessary to describe the fully deformed shape of the structure is used in the equations instead of the excessive forces used in the force methods. When the simultaneous equations that result are solved, these displacements are determined and then substituted into the original equations to determine the various internal forces. This method includes consistent distortions, Castiglione's theorems, and slope deflection. This method is primarily of historical interest and almost never used in practice. However, it forms the basis for modern methods of analysis, this method for analyzing statically indeterminate structures that are commonly used today in the structural engineering profession.

Column analogy provides a simplification of the solution as present in the plane frame example; this method is not as of yet applicable independent of other 
ways in the analysis of multi-span or multi-story frames. Luckily the other objective of this investigation is to retrieval the use of the forgotten column analogy technique for analysis of frame structures. The presented procedure makes use of this method briefly, to begin the solution, of the frame structure. During the solution, the contribution and exploited of summitry can be improved on this method [5].

\section{OBJECTIVES}

The main objectives of this investigation are to comprehend and clarify the influence of symmetry in structural analysis in civil engineering projects and detect how this influence contributes to the simplification of analysis procedures with time-saving during this process.

\section{METHODOLOGY}

It's commonly understood that, if a structure with a particular type of symmetry subjected to loading with identical symmetry, considerable time and computational effort can be saved by analyzing only the symmetry substructure. It less commonly understood that this is also true if the structure is subjected to any general loading. In this study, these three methods of analyzing and contributions of symmetry in different analysis methods of the plane frame explained in detail.

\section{The Force Method}

The displacement method (force method) is an excessive method for analysis of statically indeterminate frames subjected to various external actions. The displacement method is active, especially for analyzing advanced structures with a large number of redundant constraints. The two techniques of the displacement method applied in structural engineering. One uses the expanded technology and the other the canonical technique equations. The displacement method was introduced in 1826 by C. L. Navier (17851836). The displacement method in the canonical form is brought to elegant simplicity and contains a deep fundamental idea. This form offers a unified and rigorous convenient algorithm for the analysis of different statically indeterminate structures. Moreover, the displacement method in the canonical form is a very effective tool for the special parts of structural analysis, such as stability and structural dynamics [1].

\section{Matrix Stiffness Method}

Matrix stiffness method (MSM) is a modern, sturdy method of analysis of engineering structures. It's an effective method and extensive application that associated with the availability of new computers and current computer programs. The MSM allows performing a detailed analysis of any advanced 2D and 3D engineering structures and grosses into account various features of a structure and loading.

The method produces many techniques and a set of new concepts. They are a finite element, global and local coordinate systems, possible displacements of the ends, ancillary diagrams, initial matrices, stiffness matrix of separate part, and structure as a whole. This method uses the knowledge of the displacement method and contains its further development; random structure should present as a set of finite elements and three aspects of any problem a static, geometrical, and physical should present in matrix form. The MSM does not demand of the constructing bending moment diagram (BMD) caused by unit primary unknowns in the primary system. Instead, it is necessary to prepare a few initial matrices according to robust algorithms and perform matrix procedures by computer using the standard programs. At present, MSM developed with great detail [1].

\section{Column Analogy Method}

The method of column analogy is an excellent implement for the analysis of statically indeterminate structures in the form of single-cells such as single-span and closed frames, it is projected by prof. Hardy Cross between (1930 and 1945). It is beneficial in taking care of side sway without any special consideration like, for instance, in the analysis of moment distribution. Also, in the analysis of multi-cell structures with few cells by the method of virtual work, column analogy provides a simplification of the solution by choosing a closed-cell as the primary system. Nevertheless, column analogy is not as of yet applicable independently of other methods in the analysis of multi-span or multi-story frames [2].

\section{RESULTS AND DISCUSSION}

Considering the plane frame shown

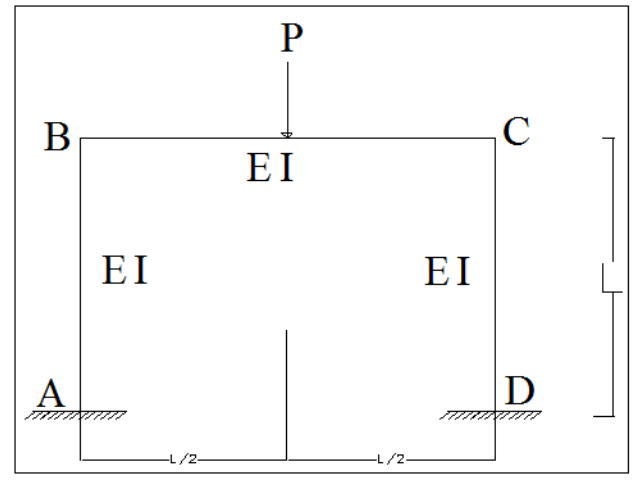

Figure -1: Symmetrical plane frame

No. of member $=3$, No. of reaction $=4$

No. of joint $=4$

Additional equilibrium equation $(\mathrm{n})=0$

Degree of statistical indeterminacy (D.S.I)

D.S.I $=3 m+r-3 j-n$

D.S.I $=3 * 3+6-3 * 4-0$

D.S.I $=3$

No. of external redundant $=\mathrm{r}-\mathrm{n}-3$

No. of external redundant $=6-3-0$

No. of external redundant $=3$

No. of internal redundancy 
No. of internal redundant $=$ D.S.I - No. of external redundant

No. of internal redundant $=3-3=0$

Degree of kinematic indeterminacy (D.K.I)

D.K.I=No. of joints degree of freedom - No. of reaction

D.K.I $=4 * 3-6$

D.K.I $=6$

\section{Solution procedure by force (flexibility) method}

Flexibility equation is $\mathrm{Q}=\left(\mathrm{F}^{-1}\right) *[\Delta \mathrm{Q}-\mathrm{DQL}]$

Since $\Delta \mathrm{Q}=0$ then

$\mathrm{Q}=\left(\mathrm{F}^{-1}\right) *[-\mathrm{DQL}]$

Step 1:

Determined of flexibility inverse matrix $\left(\mathrm{F}^{-1}\right)$ by using a product of (BMD) area method Let the reaction at the joint $(\mathrm{A})$
HA, VA, and MA are the redundant $(\mathrm{Q} 1, \mathrm{Q} 2$, and Q3).

For each redundant calculate (SFD) and (BMD)

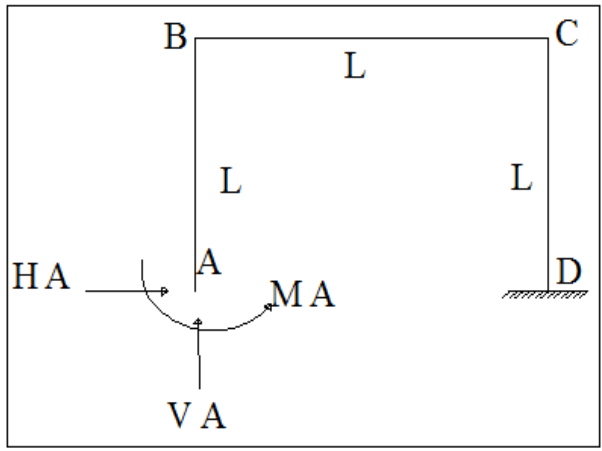

Figure -2: Statically Determinate Plane frame

if $\mathrm{Q} 1=1$

For element (AB)
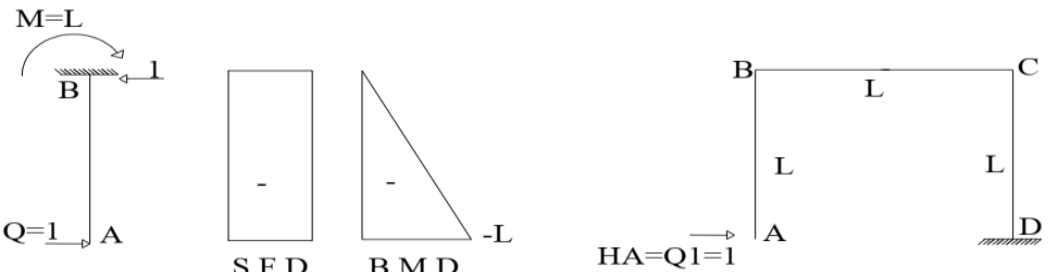

For element (B.C)

For element (C.D)

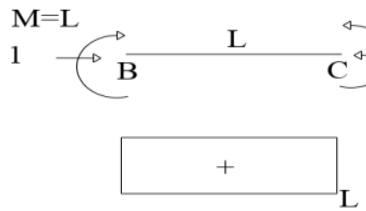

B.M.D

if $\mathrm{Q} 2=\mathrm{VA}=1$

For element (AB)

$\underset{\substack{\text { Shear force }=0 \\ \mathrm{~B} \cdot \mathrm{M}=0}}{\left.\mathrm{~B}\right|_{1} ^{1}}$
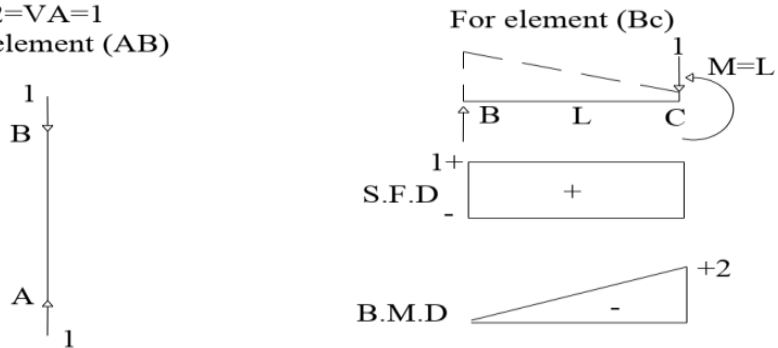

For element (CD)

Shear force $=0$

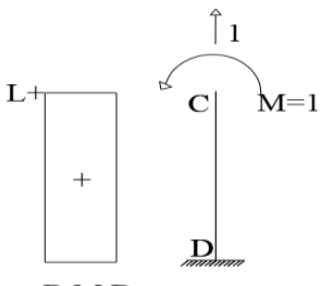

if $\mathrm{Q} 3=\mathrm{MA}=1$

For element (AB)

For element (BC)
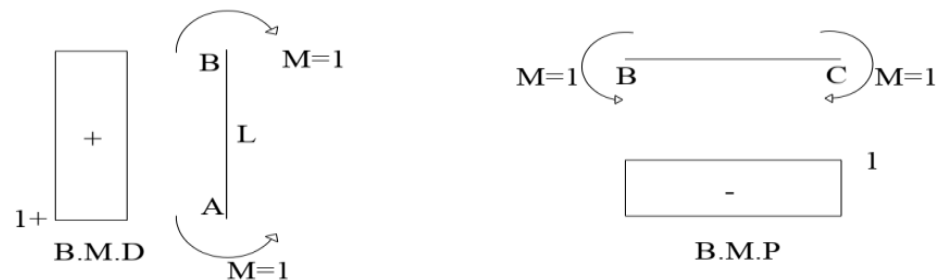

For element (CD

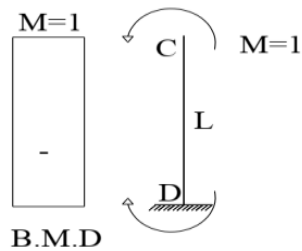




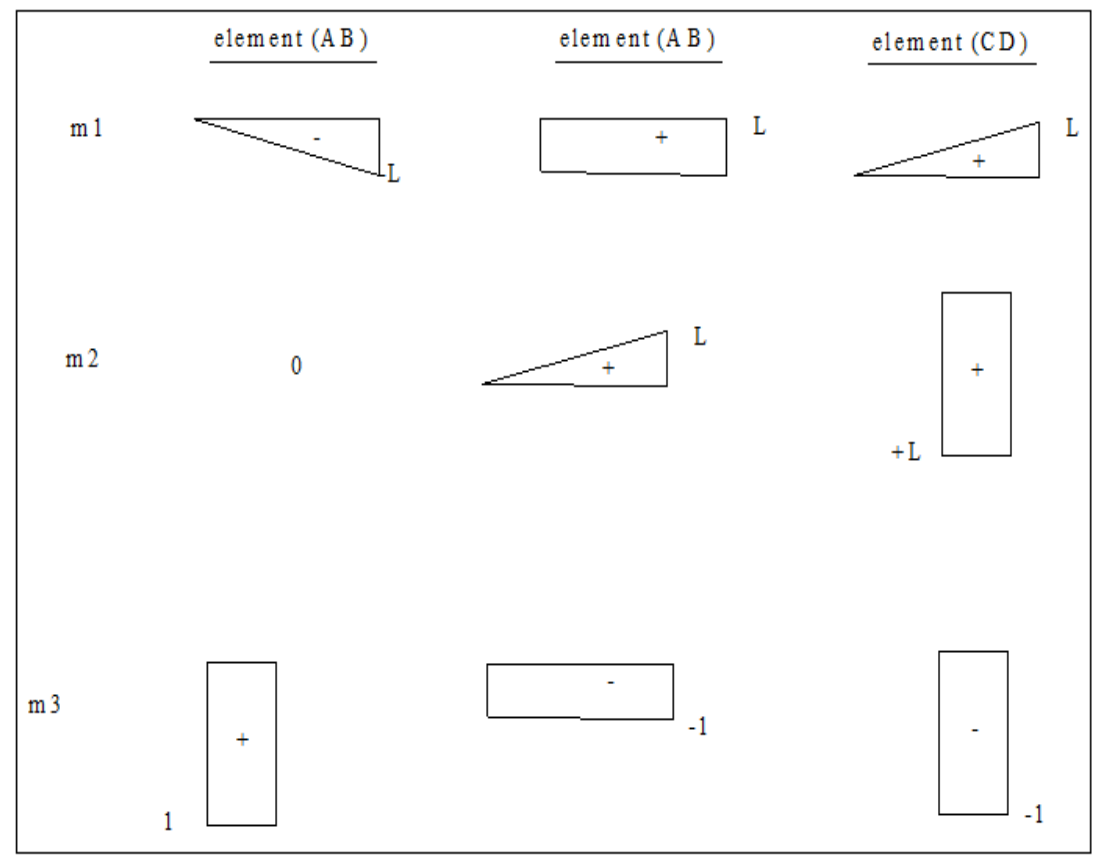

Figure -3: Summary of moment area of frame elements

Determination of matrix element

$$
\begin{aligned}
& \mathrm{F} 11=1 / \mathrm{EI} * \int \mathrm{m} 1 * \mathrm{~m} 1 * \mathrm{dx} \\
& \mathrm{F} 12=1 / \mathrm{EI} * \int \mathrm{m} 1 * \mathrm{~m} 2 * \mathrm{dx} \\
& \mathrm{F} 21=1 / \mathrm{EI} * \int \mathrm{m} 2 * \mathrm{~m} 1 * \mathrm{dx} \ldots . . \text { etc. }
\end{aligned}
$$

From the tables of area production and the Table 1, the results of the redundant are as follows:

$$
\begin{aligned}
& \mathrm{F} 11=1 / \mathrm{EI}\{1 / 3(-\mathrm{L})(-\mathrm{L})(\mathrm{L})+(\mathrm{L})(\mathrm{L})(\mathrm{L})+1 / 3(\mathrm{~L} . \mathrm{L} . \mathrm{L})\} \quad=\mathrm{L}^{3} / \mathrm{EI} \\
& \mathrm{F} 22=1 / \mathrm{EI}\{0+1 / 3(\mathrm{~L} . \mathrm{L} . \mathrm{L})+\mathrm{L} . \mathrm{L} . \mathrm{L}\}=4 \mathrm{~L} 3 / 3 \mathrm{EI} \\
& \mathrm{F} 33=1 / \mathrm{EI}\{1 * 1 * \mathrm{~L}+(-1)(-1)(\mathrm{L})+(-1)(-1)(\mathrm{L})\}=3 \mathrm{~L} / \mathrm{EI} \\
& \mathrm{F} 24=\mathrm{F} 12=1 / \mathrm{EI}\{0+1 / 2 * \mathrm{~L} * \mathrm{~L} * \mathrm{~L}+1 / 2 \mathrm{~L} * \mathrm{~L} * \mathrm{~L}\}=\mathrm{L}^{3} / \mathrm{EI} \\
& \mathrm{F} 31=\mathrm{F} 13=1 / \mathrm{EI}\{1 / 2(-\mathrm{L})(1)(\mathrm{L})+(-1)(\mathrm{L})(\mathrm{L})+1 / 2(\mathrm{~L})(-1)(\mathrm{L})\}=-2 \mathrm{~L}^{2} / \mathrm{EI} \\
& \mathrm{F} 32=\mathrm{F} 23=1 / \mathrm{EI}\{0+1 / 2(\mathrm{~L}) *(-1) *(\mathrm{~L})+(-1)(\mathrm{L})(\mathrm{L})\}=-3 \mathrm{~L}^{2} / 2 \mathrm{EI}
\end{aligned}
$$

Construction of flexibility matrix as shown below

$$
\begin{aligned}
& F=\frac{1}{E I}\left|\begin{array}{ccc}
L^{3} & L^{2} & -2 L^{2} \\
L^{3} & 4 / 3 L^{3} & -3 / 2 L^{2} \\
-2 L^{2} & -3 / 2 L^{2} & 3 L
\end{array}\right| \\
& |F|=10 L^{7}-\frac{111}{12} L^{7}=\frac{120-111}{12}=\frac{3}{4} L^{7} \\
& \left(\mathrm{~F}^{-1}\right)=\frac{1}{E I} * \frac{3}{4} L^{7}\left[\begin{array}{ccc}
\frac{2}{4} L^{4} & 3 L^{3} & \frac{9}{6} L^{5} \\
0 & -L^{4} & -\frac{1}{2} L^{5} \\
\frac{9}{6} L^{3} & -\frac{1}{2} L^{5} & -\frac{2}{4} L^{4}
\end{array}\right] \\
& \left(\mathrm{F}^{-1}\right)=\frac{1}{E I}\left[\begin{array}{ccc}
\frac{7}{3 L^{3}} & \frac{4}{L^{3}} & \frac{14}{9 L^{2}} \\
0 & -\frac{4}{3 L^{3}} & -\frac{2}{3 L^{3}} \\
\frac{14}{9 L^{2}} & -\frac{2}{3 L^{3}} & -\frac{8}{9 L}
\end{array}\right]
\end{aligned}
$$




\section{Column analogy method}

Select the frame with the hinged end at (A) and roller end at (D) as a basic determinate structure to determine reaction and drawing (SFD), (BMD).

$$
\begin{aligned}
& \sum \mathrm{M}_{\mathrm{A}}=0 \\
& \mathrm{P} * \frac{1}{2}-\mathrm{R}_{\mathrm{D}} * \mathrm{~L}=0 \\
& \mathrm{R}_{\mathrm{D}} * \mathrm{~L}=\frac{\mathrm{PL}}{2} \\
& \mathrm{R}_{\mathrm{D}}=\frac{\mathrm{P}}{2} \\
& \sum \mathrm{F}_{\mathrm{y}}=0 \\
& -\mathrm{P}+\frac{\mathrm{P}}{2}+\mathrm{R}_{\mathrm{A}}=0 \\
& \mathrm{R}_{\mathrm{A}}=\mathrm{P}-\frac{\mathrm{P}}{2}=\frac{\mathrm{P}}{2} \\
& \sum \mathrm{F}_{\mathrm{X}}=0 \rightarrow H A=\emptyset
\end{aligned}
$$

For element BC

No moment at $\mathrm{B}$ and $\mathrm{C}$

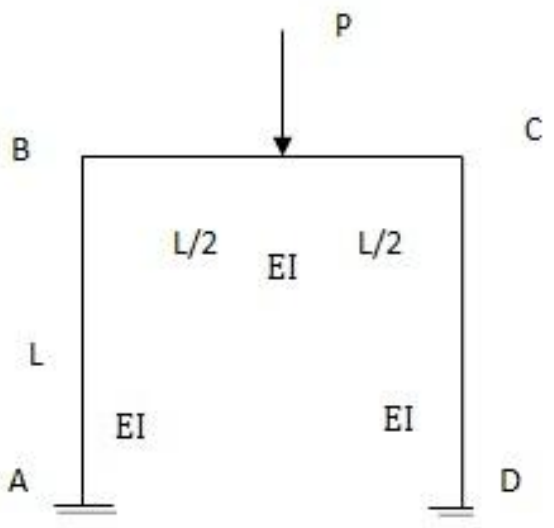

Figure-4: Basic determinate plane frame

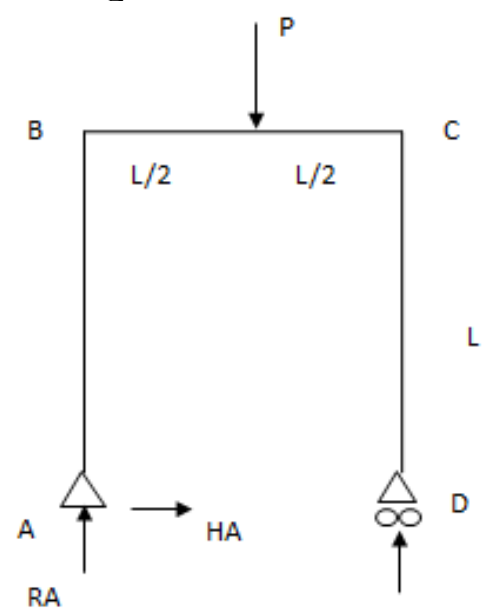

$\mathrm{RD}$

Figure-5: Analogious column

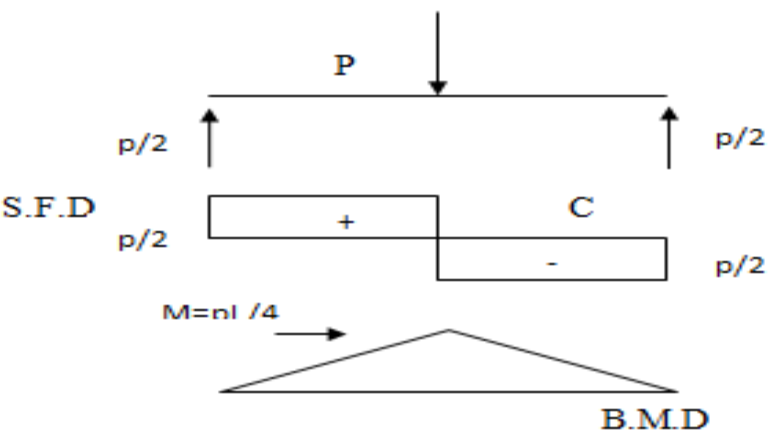

Figure-6: Analysis of plane frame by stiffness method

Analogous column properties

Area $\mathrm{A}=\left(\frac{1}{\mathrm{EI}} * \mathrm{~L}\right)+\left(\frac{1}{\mathrm{EI}} * \mathrm{~L}\right)+\left(\frac{1}{\mathrm{EI}} * \mathrm{~L}\right)=\frac{3 \mathrm{~L}}{\mathrm{EI}}$

Symmetric axis is the principal axis y-y 
Determine the area centroid distance from the axis $(\mathrm{x}-\mathrm{x})$ by taking area moment about $\mathrm{BC}$

$\mathrm{A} * \mathrm{y}_{\mathrm{c}}=\frac{\mathrm{L}}{\mathrm{EI}}+\frac{\mathrm{L}}{2}+\frac{\mathrm{L}}{\mathrm{EI}}+\frac{\mathrm{L}}{\mathrm{EI}}+\frac{\mathrm{L}}{2} * 0$

$\frac{3 \mathrm{~L}}{\mathrm{EI}} * \mathrm{y}_{\mathrm{c}}=\frac{\mathrm{L}^{2}}{\mathrm{EI}}$

$\mathrm{y}_{\mathrm{c}}=\frac{\mathrm{L}}{3}$

Moment of inertia about (x-x) axis (Ixx)

$\mathrm{Ix}=\frac{1}{\mathrm{EI}}\left(\left(\frac{1}{12} * 1 * \mathrm{~L}^{3}\right)+(1 * \mathrm{~L})\left(\mathrm{L}-\frac{\mathrm{L}}{3}\right)^{2}\right) * 2+\left(\mathrm{L} * \frac{1}{\mathrm{EI}}\right) *\left(\frac{\mathrm{L}}{3}\right)^{2}$

$\mathrm{Ix}=\frac{7 \mathrm{~L}^{3}}{6 \mathrm{EI}}$

Moment of inertia about (y-y) axis ( Iyy)

$\mathrm{Iy}=\left(\frac{\left((1 / \mathrm{EI})^{3} * \mathrm{~L}\right)}{12}+\left(\frac{1}{\mathrm{EI}} * \mathrm{~L}\right)\left(\frac{\mathrm{L}}{2}\right)^{2}\right) * 2+\left(\frac{\mathrm{L}^{3}}{12 \mathrm{EI}}\right)+0$

$\mathrm{P} / 2$

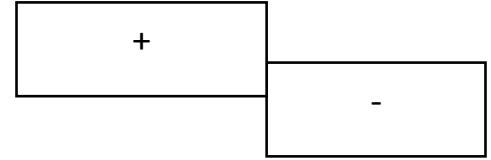

$\mathrm{P} / 2$

S.F.D

$\mathrm{Iy}=\frac{7 \mathrm{~L}^{3}}{12 \mathrm{EI}}$

Load diagram properties:

Total load area $=\mathrm{p}=$ area of

$$
\frac{\mathrm{MS}}{\mathrm{EI}}=\frac{1}{2}(\mathrm{~L}) * \frac{\mathrm{PL}}{4 \mathrm{EI}}=\frac{\mathrm{PL}^{2}}{8 \mathrm{EI}}
$$

C.G of load from $B \quad y_{s}=\frac{L}{2}$ due to symmetry

$\mathrm{e}_{\mathrm{y}}=\mathrm{y}_{\mathrm{s}}-\mathrm{y}_{\mathrm{c}}=0$

$\mathrm{M}_{\mathrm{y}}=\mathrm{P} * \mathrm{e}_{\mathrm{y}}=0$

$\mathrm{e}_{\mathrm{x}}=\mathrm{x}_{\mathrm{S}}-\mathrm{y}_{\mathrm{c}}=\frac{\mathrm{MS}}{\mathrm{EI}}=\frac{\mathrm{L}}{2} * \frac{\mathrm{L}}{3}=\frac{\mathrm{L}}{6}$

$\mathrm{M}_{\mathrm{X}}=\mathrm{P} * \mathrm{e}_{\mathrm{X}}=\frac{\mathrm{PL}^{2}}{8 \mathrm{EI}} * \frac{\mathrm{L}}{6}=\frac{\mathrm{PL}^{3}}{48 \mathrm{EI}}$

$\mathrm{Mi}_{\mathrm{A}}=\frac{\mathrm{P}}{\mathrm{A}} \mp \frac{\mathrm{My}}{\mathrm{Iy}} \mathrm{x} \mp \frac{\mathrm{Mx}}{\mathrm{Ix}} \mathrm{y}$

$\mathrm{Mi}_{\mathrm{A}}=\frac{\mathrm{PL}^{2} / 8 \mathrm{EI}}{\frac{3 \mathrm{~L}}{\mathrm{EI}}}+\mathrm{O}-\frac{\mathrm{PL}^{3} / 48 \mathrm{EI}}{7 \mathrm{~L}^{3} / 6 \mathrm{EI}}\left(\mathrm{L}-\frac{\mathrm{L}}{3}\right)=\frac{-5}{168} \mathrm{PL}$
B

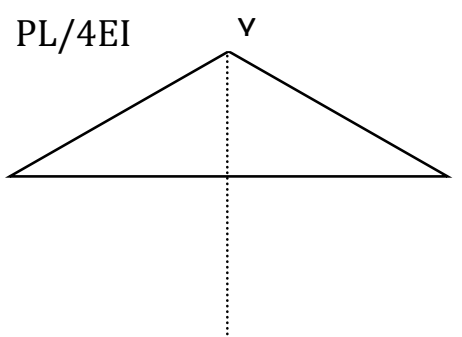

B.M.D

C

D

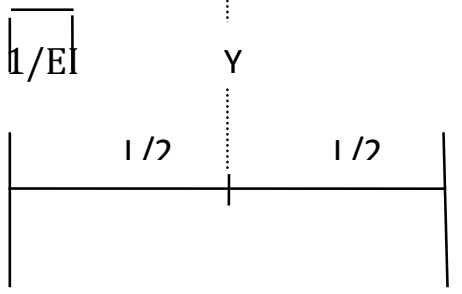




$$
\begin{aligned}
& \mathrm{Mi}_{\mathrm{B}}=\frac{\mathrm{PL}^{2} / 8 \mathrm{EI}}{\frac{3 \mathrm{~L}}{\mathrm{EI}}}+0-\frac{\mathrm{PL}^{3} / 48 \mathrm{EI}}{7 \mathrm{~L}^{3} / 6 \mathrm{EI}}\left(\frac{\mathrm{L}}{3}\right)=\frac{5}{168} \mathrm{PL} \\
& \mathrm{Mi}_{\mathrm{C}}=\frac{\mathrm{PL}^{2} / 8 \mathrm{EI}}{\frac{3 \mathrm{~L}}{\mathrm{EI}}}+\mathrm{O}-\frac{\mathrm{PL}^{3} / 48 \mathrm{EI}}{7 \mathrm{~L}^{3} / 6 \mathrm{EI}}\left(\mathrm{L}-\frac{\mathrm{L}}{3}\right)=\frac{9}{168} \mathrm{PL} \\
& \mathrm{Mi}_{\mathrm{D}}=\frac{\mathrm{PL}^{2} / 8 \mathrm{EI}}{\frac{3 \mathrm{~L}}{\mathrm{EI}}}+\mathrm{O}-\frac{\mathrm{PL}^{3} / 48 \mathrm{EI}}{7 \mathrm{~L}^{3} / 6 \mathrm{EI}}\left(\mathrm{L}-\frac{\mathrm{L}}{3}\right) \frac{-5}{168} \mathrm{PL} \\
& M_{A}=M_{S} A-M_{i} A=0-\left(-\frac{5}{168} P L\right)=\frac{5}{168} P L=M_{D} \\
& M_{B}=M_{S} B-M_{i} B=0-\left(\frac{9}{168} P L\right)=-\frac{9}{168} P L=M_{C}
\end{aligned}
$$

From above procedure and due to symmetry the plane frame reaction $\left(\mathrm{M}_{C}\right.$ and $\left.\mathrm{M}_{D}\right)$ can be determined which is equal to $\left(M_{B}\right.$ and $\left.M_{A}\right)$; respectively, with considering the assignment and direction of action on the plane frame

\section{STIFFNESS METHOD}

The frame has 6 degrees of kinematic indeterminacy at the joint $(B, C)$

At the joint $(\mathrm{C})$ let $\mathrm{D}_{1}=1$

Element BC

$\mathrm{S}_{11}=\frac{E A}{L}$

$\mathrm{S}_{21=0}$
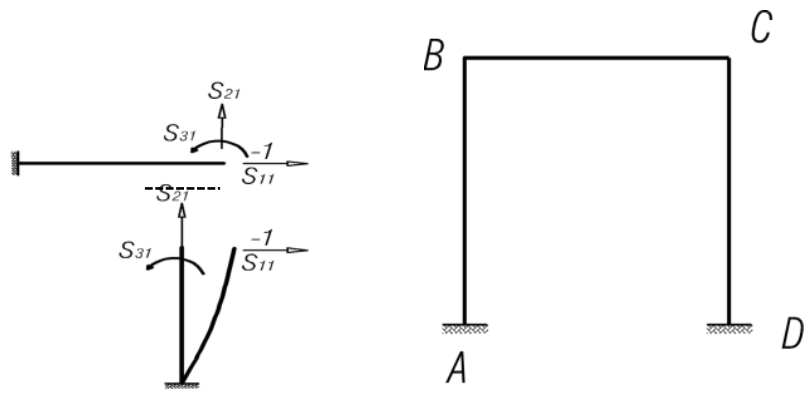

$\mathrm{S}_{31=0}$

Element CD

$\mathrm{S}_{11}=\frac{12 E I}{L^{3}}$

$\mathrm{S}_{21=0}$

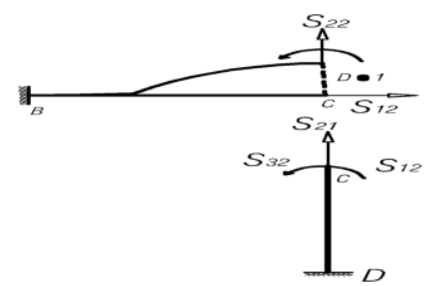

$\mathrm{S}_{31}=\frac{6 E I}{L^{2}}$

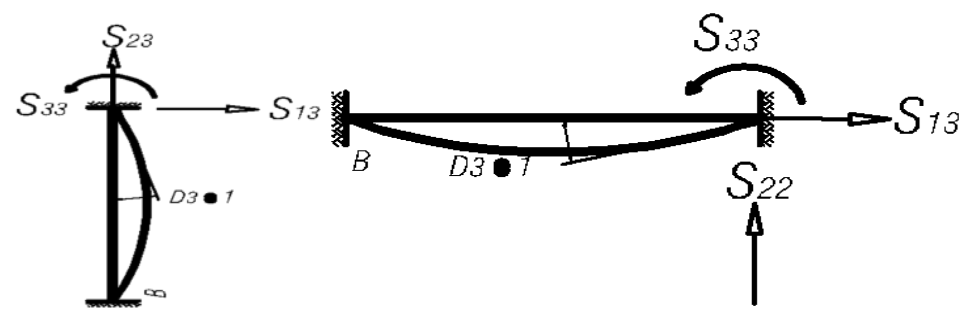

$\mathrm{S}_{11}=\frac{E A}{L}+\frac{12 E I}{L^{3}}$ 
$\mathrm{S}_{21=0}$

$\mathrm{S}_{31}=\frac{6 E I}{L^{2}}$

At the joint $(\mathrm{C})$ let $\mathrm{D}_{2}=1$

Summery

$$
\begin{aligned}
& \mathrm{BC} / \mathrm{S}_{12=0}, \mathrm{~S}_{22}=\frac{12 E I}{L^{3}}, \mathrm{~S}_{32}=\frac{6 E I}{L^{2}} \\
& \mathrm{CD} / \mathrm{S}_{12=0}, \mathrm{~S}_{22}=\frac{E A}{L}, \mathrm{~S}_{32}=0
\end{aligned}
$$

$$
\begin{aligned}
& \mathrm{S}_{12}=0 \\
& \mathrm{~S}_{22}=\frac{12 E I}{L^{3}}+\frac{E A}{1 L} \\
& \mathrm{~S}_{32}=\frac{-6 E I}{L^{2}}
\end{aligned}
$$

At the joint (C) let $\mathrm{D}_{3}=1$

$$
\begin{array}{ll}
\mathrm{BC} / & \mathrm{S}_{13}=0, \mathrm{~S}_{23}=\frac{-6 E I}{L^{2}}, \mathrm{~S}_{33}=\frac{4 E I}{L} \\
\mathrm{CD} / & \mathrm{S}_{13}=\frac{6 E I}{L^{2}}, \quad \mathrm{~S}_{23}=0, \mathrm{~S}_{33}=\frac{4 E I}{L}
\end{array}
$$

Summery

$$
\begin{aligned}
& \mathrm{S}_{13}=\frac{6 E I}{L^{2}}, \mathrm{~S}_{23}=\frac{-6 E I}{L^{2}}, \mathrm{~S}_{33}=\frac{8 E I}{L} \\
& \mathrm{SJ}_{C \text { matrix }}=\left[\begin{array}{ccc}
\frac{12 \mathrm{EI}}{\mathrm{L}^{3}} & 0 & \frac{-6 \mathrm{EI}}{\mathrm{L}^{2}} \\
0 & \frac{12 \mathrm{EI}}{\mathrm{L}^{3}} & \frac{-6 \mathrm{EI}}{\mathrm{L}^{2}} \\
\frac{6 \mathrm{EI}}{\mathrm{L}^{2}} & \frac{-6 \mathrm{EI}}{\mathrm{L}^{2}} & \frac{4 \mathrm{EI}}{\mathrm{L}}
\end{array}\right]
\end{aligned}
$$

Duo to symmetry after considering the assignment on action direction

$$
\mathrm{SJ}_{\mathrm{C}} \text { matrix }=\text { matrix } \mathrm{SJ}_{\mathrm{B}}
$$

From the above procedure and duo to symmetry, the plane frame stiffness matrix with size $(6 * 6)$ for analysis can be produced by the combination of SJC matrix and matrix $\mathrm{SJ}_{\mathrm{B}}$ with considering the assignment and direction of action on the plane frame.

\section{CONCLUSIONS}

- In force method by using the area moment distribution from the tables, the contribution of symmetry has an indirect effect of shrinkage the procedure of plane frame analysis.

- In the column analogy and the stiffness matrix methods, the contribution of symmetry has a direct effect to shrinkage the procedure of plane frame analysis.

- During the whole procedure of the structural analysis, the symmetry has a significant effect of simplifying the procedure and save the time.

\section{REFERENCES}

1. Cross, H. (1930). The column analogy: analysis of elastic arches and frames. University of Illinois at Urbana Champaign, College of Engineering. Engineering Experiment Station.

2. Lui, E. M., \& Chen, W. F. (1986). Analysis and behavior of flexibly-jointed frames. Engineering Structures, 8(2), 107-118.

3. Weaver, W., \& Gere, J. M. (1990). Fundamentals of the Flexibility Method. In Matrix Analysis of Framed Structures (pp. 55-116). Springer, Boston, MA.

4. Karnovsky, I. A., \& Lebed, O. (2010). Advanced methods of structural analysis. Springer Science \& Business Media.

5. Badir, A., \& Badir, M. (2012). Column Analogy in Multi-Cell Structures with Fixed Columns. Electronic Journal of Structural Engineering, 12, 1.

6. Ansari, S. J., \& Bhole, S. (2016). Comparative study of symmetric \& asymmetric L-shaped \& Tshaped multi-storey frame building subjected to gravity \& seismic loads with varying stiffness. International Journal of Science Technology \& Engineering, 2:734-742. 